\title{
Video analysis using a shaking camera
}

Videoanálise usando uma câmera trêmula

\author{
V. L. B. de Jesus ${ }^{* 1}$, D. G. G. Sasaki \\ ${ }^{1}$ Instituto Federal de Educação, Ciência e Tecnologia do Rio de Janeiro, Nilópolis, RJ, Brasil. \\ ${ }^{2}$ Centro Federal de Educação Tecnológica Celso Suckow da Fonseca, Maracanã, RJ, Brasil.
}

Received on August 18, 2021. Revised on September 12, 2021. Accepted on September 14, 2021.

\begin{abstract}
To perform a reliable video analysis, it is mandatory to avoid shaking the camera while taking the video, normally using a tripod for smartphones/cameras. But there are some situations which the only chance to make the video is using your hands and it is almost impossible to avoid shaking the camera even trying your best. Imagine the following situation: a volleyball is obliquely launched, and the video is filmed by hand. Then, a point that is fixed in relation to the ground is chosen as the origin of a ground fixed reference frame. Despite being a ground fixed point, it will appear shaky in images captured by the handheld camera. Thereby, two standard video analyses are performed, one from the ground fixed point random shaking and one from the ball's trajectory, both in relation to the default reference frame of the video analysis software. Lastly, to implement the video analysis of the relative ball movement it is enough to subtract the position coordinates of the ball's movement by the position coordinates of the ground fixed point tremble, at each instant of time. The graphs of the position and velocity components versus time are presented, and the results are discussed.
\end{abstract}

Keywords: Physics teaching, reference frame, relative movement, video analysis, Tracker.

Em uma videoanálise confiável, evita-se balançar a câmera durante a filmagem, normalmente usando um tripé para smartphones/câmeras. Mas existem algumas situações em que a única chance de fazer o vídeo é usando as mãos e é quase impossível evitar balançar a câmera mesmo tentando o seu melhor. Imagine a seguinte situação: uma bola de vôlei é lançada obliquamente e o vídeo é filmado à mão. Em seguida, um ponto que é fixo em relação ao solo é escolhido como a origem de um referencial fixo do solo. Apesar de ser um ponto fixo no solo, ele aparecerá trêmulo nas imagens capturadas pela câmera. Desse modo, duas videoanálises padrão são realizadas, uma do tremor aleatório do ponto fixo no solo e outra da trajetória da bola, ambas em relação ao referencial padrão do software de análise de vídeo. Por fim, para implementar a videoanálise do movimento relativo da bola, basta subtrair suas coordenadas de posição pelas coordenadas de posição do ponto fixo do solo, a cada instante de tempo. Esta técnica reduz drasticamente o efeito de vibração nas variáveis cinemáticas. Os gráficos dos componentes de posição e velocidade em função do tempo são apresentados e os resultados são discutidos.

Palavras-chave: Ensino de física, Sistema de referência, movimento relativo, videoanálise, Tracker.

\section{Introduction}

Video analysis is a fruitful and efficient resource to track movements and obtain large amount of kinematic data and its graphs [1, 2. However, to obtain the better results it is quite important to meet some essential requirements to avoid systematic errors: stable camera mounting, no panning shot, maximize the camera-tosubject distance, maximize the image size, align the camera's optical axis perpendicular to the plane of motion, and insert a scaling object in same plane of the center of mass trajectory to prevent parallax problems [2 4].

In fact, a fixed camera is ubiquitous recommendation to guarantee the quality of the video and its consistence with a fixed laboratory reference frame. Nevertheless, it is not always possible, and the opportunity to film is sometimes unique. Therefore, in these cases the only way is to use the camera or the smartphone holding

\footnotetext{
${ }^{*}$ Correspondence email address: vitor.jesus@ifrj.edu.br
}

it by hand as firm as possible and take a shot. But the film will never be the same as if it would be shot using a tripod or a fixed holder. Consequently, the video analysis will become extremely poor and unreliable. To circumvent such a problem and overcome the shaking of the camera, this work proposes the following technique: (i) choose a point in the snapshot that is known to be at rest in relation to the laboratory reference frame, such as a piece of the ground or an object standing in the picture (ground fixed point), as reference; (ii) despite being a ground fixed point, it will appear shaky in images captured by the handheld camera. Then, make the usual video analysis procedure of this ground fixed point, in relation to the default reference frame of the video analysis software; (iii) make the standard video analysis of the moving object, again in relation to the default reference frame of the video analysis software (iv) carry out a vectorial subtraction, i.e., subtract the position coordinates of the object movement by the position coordinates of the ground fixed point tremble, 
at each instant of time. In this way the shaking of the camera will be minimized (or even vanished) because both the moving object and the ground fixed point (relative reference frame) have identical tremble in the snapshot. This technique is quick and easy; therefore, it can be used in experimental classes in both high school and undergraduate courses.

\section{An Example of the Technique}

A video analysis of a volleyball obliquely launched was performed during the morning of a sunny day on the beach. The launched volleyball (Mikasa - approximate weight of 260-280 g; 65-67 cm circumference; 20.7$21.3 \mathrm{~cm}$ diameter) was filmed using a $30 \mathrm{fps}$ 16:9 FHD 1080p Samsung Galaxy J4+ smartphone model SMJ415G. The video was filmed by hand from about $3 \mathrm{~m}$ away to cover all movement and avoid the edge distortions of the camera lens. The free software Tracker was used to analyze the video 1 .

From this distance from the camera, the visual angle of the ball is very small, so even a slight hand tremor causes a scattering of the $x y$ coordinates of the order of magnitude of the ball's diameter, for all distance measurements. All distances measurements are evaluated using the own ball's diameter as Tracker scale (dark blue line under the ball in the Fig. 1). This choice of moving object dimensions as the Tracker scale is suitable because avoid the parallax error [2 4].

Figure 17 shows the screenshot of the usual video analysis procedure, in relation to default Tracker reference

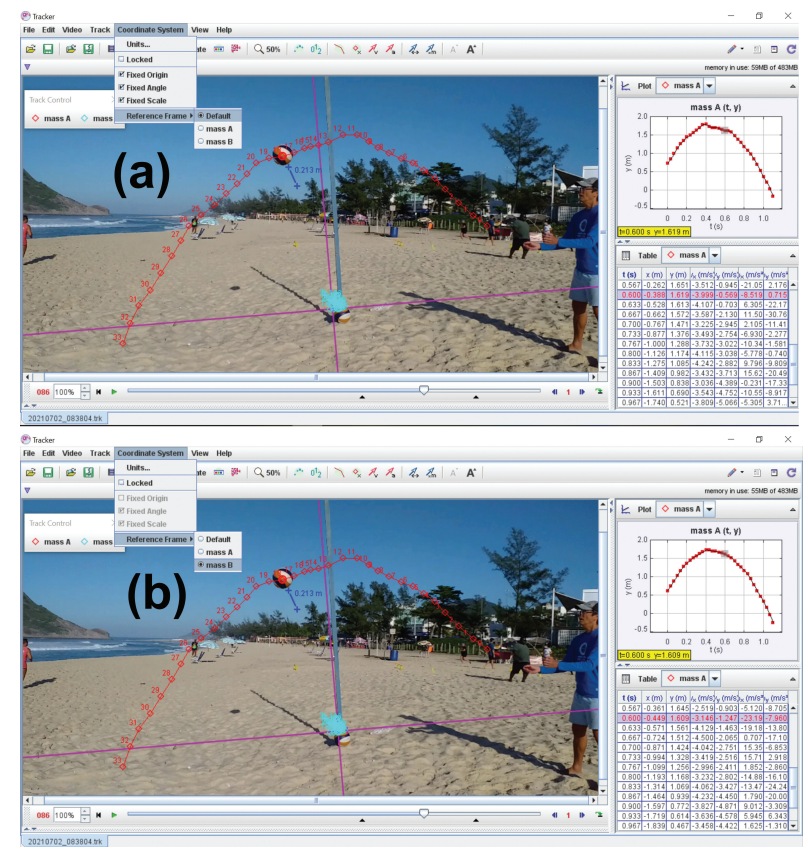

Figure 1: Screenshot of the Tracker software presenting the usual video analysis procedure of the ball's movement. (a) Default Tracker reference frame. (b) Ground fixed reference frame.

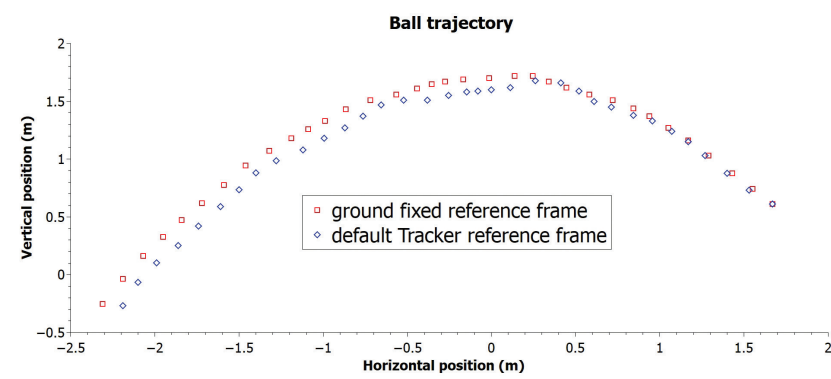

Figure 2: The volleyball trajectory considering both reference frames.

frame. It is evident in the image the shaky red dots that represent positions of the ball at each instant and the position graph on the right. Further, the shaky light blue dots represent a ground fixed point tremble. Figure $1 \mathrm{~b}$ represents the same image, but now the position graph on the right is relative to the ground fixed reference frame (relative movement). In this relative frame of reference, the ball positions appear to fit the expected parabolic trajectory. This reference frame change can be easily performed by a simple Tracker tool. In fact, when the coordinate system is changed to the ground fixed point (Mass B in the Fig. 1p), the subtraction of each coordinate as a function of time is done automatically.

The Fig. 2 presents the whole volleyball trajectory in both mentioned reference frames. Here it is also clear that the trajectory is affected by the shaking of the camera, and the correction using the ground fixed point as a reference frame (relative movement) minimizes the discrepancies.

In the Fig. 3 is depicted the graphs of position and velocity as a function of time of the ball using both default Tracker reference frame and the ground fixed reference frame (relative movement). The discrepancies are more remarkable in the cases of velocity graph. As these physical quantities are derivatives of the position coordinates, the worse the fluctuations, the worse the derivatives.

The values of the acceleration of gravity obtained from the parabolic fit of the graph of the position versus time are $9.848(65) \mathrm{m} / \mathrm{s}^{2}$ and $9.37(10) \mathrm{m} / \mathrm{s}^{2}$ from ground fixed and default Tracker reference frames, respectively. The acceleration of gravity can also be obtained from the linear fit of the graph velocity versus time are $9.887(22) \mathrm{m} / \mathrm{s}^{2}$ and $9.465(34) \mathrm{m} / \mathrm{s}^{2}$ from ground fixed and default Tracker reference frames, respectively. In both cases the uncertainties obtained from the ground fixed reference frame are smaller than the default Tracker reference frame. Indeed, comparing the standard value of the acceleration of gravity, $9.7877394(2) \mathrm{m} / \mathrm{s}^{2}[2$, with the obtained values from the parabolic fit of the graph of the position versus time, the relative errors are given by $0.6 \%$ (ground fixed reference frame) and $-4.3 \%$ (default Tracker reference frame). In the case of the linear fit of the graph velocity versus 

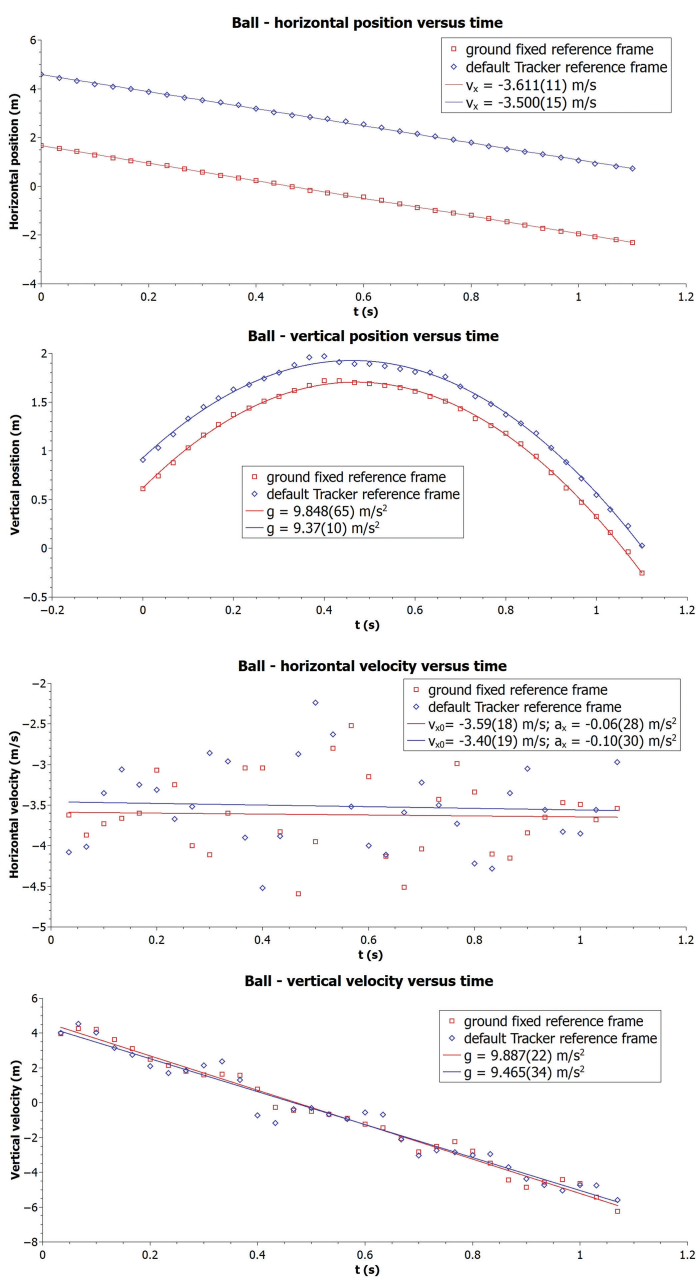

Figure 3: Graphs of position and velocity as a function of time using both the usual procedure (default Tracker reference frame) and the ground fixed reference frame (relative reference frame).

time the relative errors are $1.0 \%$ (ground fixed reference frame) and $-3.3 \%$ (default Tracker reference frame).

\section{Conclusions}

The proposed technique to perform video analysis of situations in which a movement is filmed without the use of a fixed and stable camera has proven to be efficient in minimizing, or even eliminating, the shaking effect of the camera on raw data and its kinematics graphics. For that, it is needed that both the moving object and its relative ground fixed point (relative movement) have identical shaking in the snapshot. Only a qualitative analysis is enough to reveal that the tremble of the position points, in relation to default Tracker reference frame can be minimized through a simple change to the ground fixed reference frame. A visual comparison between ball's trajectory in both reference frames shows that only in the ground fixed reference frame does the ball have a parabolic movement. Furthermore, this simple procedure assures that position data collected under an unfavorable circumstance can be corrected to provide reliable quantitative results. In fact, the experimental value for the gravity acceleration in the ground fixed reference frame is more accurate and precise than the value obtained using the default Tracker reference frame.

\section{Acknowledgments}

We would like to thank Leonardo L. Jadjeski and Kuo Ton-Hau for their help in the filming of the experiment presented in this work.

\section{References}

[1] Tracker Video Analysis and Modeling Tool, http://phys lets.org/tracker/, accessed in Feb. 2019.

[2] Vitor L.B. de Jesus, Experiments and Video Analysis in Classical Mechanics (Springer, Cham, 2017).

[3] J. Stephens, M. Bostjancic and T. Koskulitz, Physics Teacher 57, 193 (2019).

[4] T. Martin, K. Frisch and J. Zwart, Physics Teacher 58, $195(2020)$ 